\title{
Preference-based segmentation: A study of dish preferences among Vietnamese teenagers
}

\author{
VU THI HOA \\ Nha Trang University-hoavt@ntu.edu.vn \\ SKALLERUD KÅRE \\ The Arctic University of Norway - kare.skallerud@uit.no
}

\begin{abstract}
ARTICLE INFO ABSTRACT
\end{abstract}
Article history:

Received:

Oct. 12,2016

Received in revised form:

Jan. 12, 2016

Accepted:

Mar. 31, 2017

Keywords:

Food preferences

Teenagers

Vietnam
The purpose of this paper is to evaluate the usefulness of preferencebased segmentation in understanding food-related behavior among Vietnamese teenagers. A sample of 413 teenagers in secondary and high schools in three different regions is used. Their preferences for 36 common Vietnamese dishes are evaluated. Four segments based on their preferences are identified, including food likers (29\%), poultry dislikers $(27 \%)$, seafood dislikers (19\%), and pork dislikers $(25 \%)$. Differences between segments are profiled by a diverse set of variables including consumption frequencies, food choice motives, attitudinal variables, and socio-demographic variables. Dish preferences appear to be an appropriate basis for segmentation of Vietnamese adolescents. The differences found across the clusters for the differentiating variables can provide the basis for developing marketing strategies to target different segments, and also theoretical and practical implications are accordingly discussed. 


\section{Introduction}

Adolescence is an important period in the life cycle of a person which brings about significant psychological and physiological changes. The ages regarded as part of adolescence vary by culture; as usual, adolescents are called "teenagers" or "teens," derived from the tail of the English words from "thirteen" to "nineteen" (Louw, 2002). New preferences are formed due to growing autonomy, their opportunities to eat out, and their desire to enter the adult world (Ton $\mathrm{Nu}$ et al., 1996). According to Halford et al. (2008), children's food preferences are influenced by many factors, such as weight status, food type, branding, and television food advertisements (commercials). Children also develop their food preferences as they grow, and are exposed to a variety of food items, textures, tastes and flavors (Birch, 1999). Story et al. (2002) suggested that many factors influence adolescent development of food preference, including intrapersonal (individual influences), interpersonal (social environmental influences), community environment (physical environment), and macrosystems (societal influence). The prevalence of adolescents following food recommendations is low, and gender differences are found in terms of food consumption frequency (Arechavala et al., 2016). Food preferences are recognized as playing a central role in food choices and consumption in adulthood (Logue \& Smith, 1986; Steptoe et al., 1995), and probably even more in adolescence (Birch, 1999; Drewnowski, 1997). Food preferences of adolescents affect not only their parents' decisions but also their future food consumption behavior. Thus, understanding children's food preferences and how these preferences change over time is critical for marketers to make more informed decisions on their marketing mix programs, as well as for public policy makers to tailor more effective nutrition education and dietary intervention programs (Hoelscher et al., 2002).

Segmentation allows marketers to identify distinct groups of customers whose behaviors significantly differ from others. This allows firms to adjust their marketing mix to cater for particular needs of different market segments. The segmentation base chosen to subdivide a market will depend on many factors such as "the type of product, the nature of demand, the method of distribution, the media available for market communication, and the motivation of the buyers" (Chisnall, 1985). Food and seafood consumption behavior is influenced by many interrelated factors of product attributes, personality, and cultural and social environment (Olsen, 2004; Furst et al., 1996; Shepherd, 1989). The 
basis for segmentation of food markets has varied. Demographic variables have been used (Verbeke \& Lopez, 2005), in addition to food related risk perceptions (McCarthy $\&$ Henson, 2005). The evaluation and perception of fish quality by consumers have also been used as a basis for benefit-based segmentation of Belgium seafood consumers (Verbeke et al., 2007). Previous studies demonstrated that preference- or benefit-based segmentation is a fruitful way to identify segments because it often segments actual purchase or consumption in a better way (Haley, 1968; Honkanen et al., 2004; Olsen et al., 2009). Still, not many studies have used preferences as the basis for market segmentation (Wedel \& Kamakura, 1998) even though heterogeneity among consumer preferences is probably one of the most relevant segmentation bases (Kardes, 1999; Honkanen et al., 2004, Honkanen, 2010). In this study the link between preference and food-related behaviors of teenager segments in Vietnam is investigated. The aim is to evaluate the usefulness of preference-based segmentation in understanding food-related behavior among Vietnamese teenagers.

\section{Literature review}

\subsection{Segmentation base}

The first step in the segmentation process is to classify objects/customers based on a chosen set of variables. A segmentation basis is a set of variables or characteristics used to assign potential customers to homogeneous groups (Wedel \& Kamakura, 1998). These variables can include demographic and socioeconomic characteristics, personality, values and lifestyle characteristics (psychographics), situation, product use and purchase patterns, attitudes toward products and their consumption, benefits sought in a product category, and attitudes and behavior responses toward different marketing variables like product, price, promotion or distribution (Beane and Ennis, 1987; Tynan and Drayton, 1987; Wind, 1978). Many of the early segmentation studies were based upon dividing the sample into frequent and infrequent users of a product (Honkanen \& Frewer, 2009). Personality and psychographic factors became popular in the 1980s as bases for segmentation (Quinn et al., 2007). Attitudes and benefits sought by consumers (Haley, 1968) have also been used. Consumers have also been segmented by their quality evaluation (Bernues et al., 2003; Verbeke et al., 2007), including food preferences (Delarue \& Loescher, 2004).

Studies on foods have found that taste is 
considered the most important quality attribute influencing food selection (Drewnowski, 1997; Roininen et al., 1999). Health is another issue frequently mentioned as a reason for food choices (Williams \& Hammit, 2001). Research showed that taste/distaste, instead of nutrition as suggested by their parents seems to be the key driver for children's and adolescents' food choices (Berg et al., 2000; Olsen \& Ruiz, 2008). Gummeson et al. (1996) found that the "healthiness" of the meal was not a significant contributor while personal preferences for the taste, texture, and appearance of the food had a much greater influence. Berg et al. (2000) argued that taste and distaste are more important to younger consumers while Roininen et al. (1999) concluded that elderly people are more concerned about nutrition and health. Although health and taste have been found to be important predictors of food/meal consumption, only a few studies have investigated attributes of health and taste simultaneously (Roininen et al., 1999; Olsen, 2003).

Food preference can be defined as a comparison between two or more foods which leads to choice (Rozin, 1996). A common usage in food science is linking preference to liking/taste (Rozin, 1996, Honkanen, 2010). Consumer needs or preferences for a particular product may vary considerably between individuals, segments, groups, and cultures (Ngapo et al., 2007; Nielsen et al., 1998). Previous studies have suggested that differences in preferences or benefits with products or services ultimately drive marketing or consumer segmentation (Honkanen, 2010; Honkanen et al., 2004; Olsen et al., 2009). For the reasons discussed above, dish preferences are chosen as the segmentation base. This paper will first explore the usefulness of this base in a Vietnamese setting.

\subsection{Profiling variables}

After dividing the market into groups of individuals with similar characteristics, these segments would then be profiled based on other characteristics-descriptors to highlight the differences between these groups to fulfill the accessibility requirements for effective market segmentation. Profiling is critical for the proper implementation of segmentation strategy (Wedel \& Desarbo, 2002). A segment profile describes the significantly unique characteristics of the typical buyer group in a certain market segment. The profile variables used to describe segments of food markets often include consumption frequency, food choice motives, attitudinal variables, and socio-demographic variables (Honkanen, 2010). The use of demographic variables is supported in the literature (Frank et al., 1972). However, 
the marketing literature has also shown that it is difficult to profile market segments using only traditional descriptor variables (e.g., demographics) (Wedel \& Desarbo, 2002). This study will therefore use social and family-related attitudes, interests, and lifestyle variables in addition to demographics to profile segments.

On the other hand, food liking and consumption frequency for most foods are significantly and positively related (Sukalakamala \& Brittin, 2008). The frequency of consumption may be sufficient for establishing the relative intake of foods (Horwath, 1990). According to Honkanen (2010), "food choice is another variable related to preference and different segments should then show different consumption patterns unless interfered with by other factors." Hence, consumption frequency will be compared across the preference segments.

Fishbein and Ajzen (1975) argued that attitudes represent a person's general feelings (of favorableness or unfavorableness, liking or disliking, and good or bad) toward some stimulus objects (issue, person, product, activity, etc.). A broadly accepted definition of attitude considers it as "a psychological tendency that is expressed by evaluating a particular entity with some degree of favor or disfavor" (Eagly \& Chaiken, 1993). In food context attitudes are suggested to be one of the main determinants in explaining food consumption (Olsen, 2001, 2004; Shepherd \& Raats, 1996; Verbeke \& Vackier, 2005).

Social norms and preference conflicts have a significantly positive influence on intention of fish consumption behavior in Vietnam within a family setting (Tuu et al., 2008; Cong et al., 2012). Social factors have been shown to be more important than genetic factors for the development of individual differences in food preferences (Olsen, 2004). According to a review by Rolls (1988), family environment and peers are major determinants of children's and teenagers' food preferences; however, individual variation in preferences can only be partly explained by parental influences (see Hokanen et al., 2004 for a review). As per Olsen and Ruiz (2008), discrepancies in preferences are common in family food consumption behavior as well as between parents and children. Previous studies have demonstrated that adolescents and their parents have different preferences for fish in family meals (Olsen, 2001; Olsen \& Ruiz, 2008). In this paper differences in family expectations and conflicts between teenagers and their parents about food choice across segments will be investigated. Differences emanating from environmental influences - publicity or advertising (Byrd-Bredbenner \& Grasso, 2000) and school-based nutrition 
education programs or school meal plans (Skinner et al., 2002) will also be included in the analyses.

Lifestyle has been defined simply as how one lives (Kucukemiroglu, 1999). Engel et al. (1996) gives the definition of lifestyle as a summary construct defined as patterns in which people live and spend time and money. The most widely used approach to lifestyle measurements has been activities, interests, and opinions (AlO) rating statements (Wells \& Tigert, 1977). The term "lifestyle" is used in this study to express general attitudes associated with individuals' interests and activities within their social environments (Honkanen et al., 2004). More specifically, aspects of teenagers' eating habits, attitudes toward friends, families, schoolwork, media, and social activities will be employed as profiling variables. The way they perceive themselves and how interested they are in different aspects of food (Hokanen et al., 2004) are also included.

Socio-demographic variables are potentially related to food preferences, especially age and gender (Honkanen et al., 2004; Ton $\mathrm{Nu}$ et al., 1996). In other studies young men have been shown to have lower interests in food (Ares \& Gambaro, 2007). We will also explore food preferences of adolescents in various geographical locations in Vietnam in order to examine whether geographic differences can be used as profiling variables.

\section{Data and methods}

\subsection{Data selection and sample selec- tion}

The population is teenagers in secondary and high schools aged between 12 and 20. The convenience sample $(n=413)$ features locations of Ha Noi (north), Da Nang and Nha Trang (central Vietnam), and Ca Mau (south) in 2010. Schools were approached and those who agreed to participate were included in the study. In each school, classes representing each age level were randomly selected, and a teacher instructing the teenagers distributed and collected the questionnaire.

\subsection{Measures}

The preferences are measured along a seven-point semantic differential scale (from "dislike very much" to "like very much"). This scale is in accordance with most scales used to measure food preferences, overall liking or food quality (Raats et al., 1995). Respondents were informed as follows: "In the following I would like to know your preference for each kind of dish. The level to rate a dish will increase within the seven-point scale from "1-dislike very much" to "7- like very much." The preferences are measured by the liking/taste because we believe that the general liking may produce stable segments.

Consumption frequency is measured 
using a one-year time frame with a sevenpoint scale ranging from "never" (level 1) to "12 times or more a week" (level 7) (Raats et al., 1995; Olsen, 2003; Verbeke \& Vackier, 2005; Tuu et al., 2008) in the form: "Please make a mark $\square$ for each alternative on how many times on average during the last year you have consumed any following type of dish in your meal. Please mark only one answer in each row."

The social and family-related attitudes are measured according to Ajzen (2002). The semantic differential scales are the most commonly used in measuring attitude (Ajzen, 2002). Social norms are operationalized as perceived social pressure or expectations from people in general or from specific groups or individuals (Fishbein \& Ajzen, 1975; Olsen, 2004). In this paper the influence of parents and friends mean so much to teenagers. They were also asked about the influence of others (e.g., teachers, advertisements in the media, sports stars, and pop stars) on what they eat as a meal and the conflicts between children and adults in the food chosen for family meal. These items are measured on a seven-point Likert scale anchored by "disagree strongly" (-3), "neither disagree nor agree" (0), and "agree strongly" $(+3)$. Then, these items are coded into a seven-bipolar scale $(1=-3 ; 7$ $=+3$ ).
The lifestyle operationalization is related to teenagers' eating habits, attitudes toward friends, families, schoolwork, media, and social activities, the way they perceive themselves, and how interested they are in several aspects of food (Honkanen et al., 2004; Steptoe et al., 1995). Interests in food, cooking, and other activities are measured using three items: "You are very interested in (a) cooking; (b) sports; (c) environment issues; and $(\mathrm{d})$ reading newspapers/magazines, etc." on a seven-point Likert scale. Respondents were presented with the information: "We are now suggesting several propositions about food, health, fish, etc. For every proposition suggested here, please indicate your agreement or disagreement. If you totally disagree, put a mark $₫$ under -3. If you totally agree, put a mark $\square$ under +3 , or something in between if you have another attitude or meaning."

\subsection{Analytical methods}

The main analytical method is cluster analysis used to identify segments of consumers based on dish preferences to accomplish the objectives of the study. This study used a two-stage clustering which has been found to outperform other methods in marketing and social sciences research (Punj \& Stewart, 1983). The number of clusters is determined by the use of Bayesian information criterion, and factor 
scores are used as input in the cluster analysis. In order to profile the segments, we employ consumption (shellfish, fish, beef/veal, pork, poultry, eggs, vegetables, and rice), social and family-related attitudes toward eating fish and food consumption, interest and lifestyle, and demographic data (age, gender, religion, place of living, number of family members, number of children in families, average allowance per month). This piece of insightful information is used to determine which teenager segments are ideal for the food provider to target. Specifically, crosstabs procedure performed to profile demographics variables is expected to be useful in profiling segments. Profiling social and family-related attitudes, interest and lifestyle, and fish/food consumption are processed using analysis of variance (ANOVA) with Duncan's multiple-comparison posthoc test of differences in group means between segments.

\section{Results and discussion}

\subsection{Results}

Exploratory factor analysis and test of reliability

This section begins with exploratory factor analysis and reliability test for the measures. Factor loadings of items are extracted and associated with sub-latent constructs, and then Cronbach's alphas are calculated for the most reliable measures. The primary objective of the analysis is to explore different aspects with social and family-related attitudes and lifestyle and interests, to further understand the relationship among these constructs, and to clarify how they are related to dish preferences. T-test and ANOVA are adopted to test the mean difference of the items. Factor loadings of the items and Cronbach's alpha of the constructs are presented in Table 1 . 


\section{Table 1}

Results of exploratory factor analysis and test of reliability of profiles constructs: Rotated factor patterns (Varimax)

Rotated Component Matrix ${ }^{\mathrm{a}}$

\section{Component}

\begin{tabular}{|c|c|c|c|c|c|c|c|c|c|}
\hline & 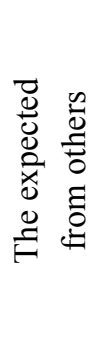 & 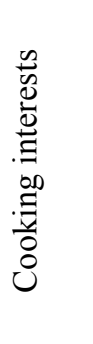 & 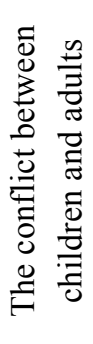 & 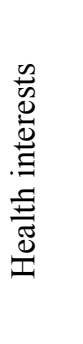 & 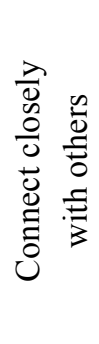 & 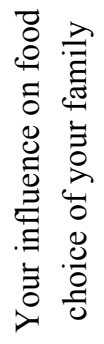 & 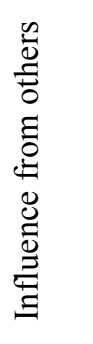 & 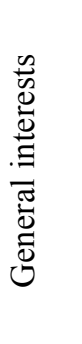 & 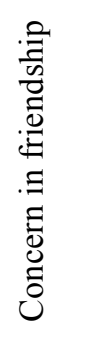 \\
\hline Cronbach's alpha & 0.77 & 0.67 & 0.65 & 0.64 & 0.63 & 0.60 & 0.62 & 0.60 & 0.61 \\
\hline Your parents expect & .857 & & & & & & & & \\
\hline $\begin{array}{l}\text { People who mean a lot } \\
\text { to you }\end{array}$ & .840 & & & & & & & & \\
\hline $\begin{array}{l}\text { The adults in your } \\
\text { household }\end{array}$ & .681 & & & & & & & & \\
\hline $\begin{array}{l}\text { You can make simple } \\
\text { dishes }\end{array}$ & & .779 & & & & & & & \\
\hline help with household & & .700 & & & & & & & \\
\hline $\begin{array}{l}\text { You are very interested } \\
\text { in cooking }\end{array}$ & & .662 & & & & & & & \\
\hline $\begin{array}{l}\text { You often feel that your } \\
\text { family disagrees }\end{array}$ & & & .748 & & & & & & \\
\hline $\begin{array}{l}\text { You are tired of your } \\
\text { parents }\end{array}$ & & & .724 & & & & & & \\
\hline $\begin{array}{l}\text { You often feel a con- } \\
\text { flict }\end{array}$ & & & .573 & & & & & & \\
\hline
\end{tabular}




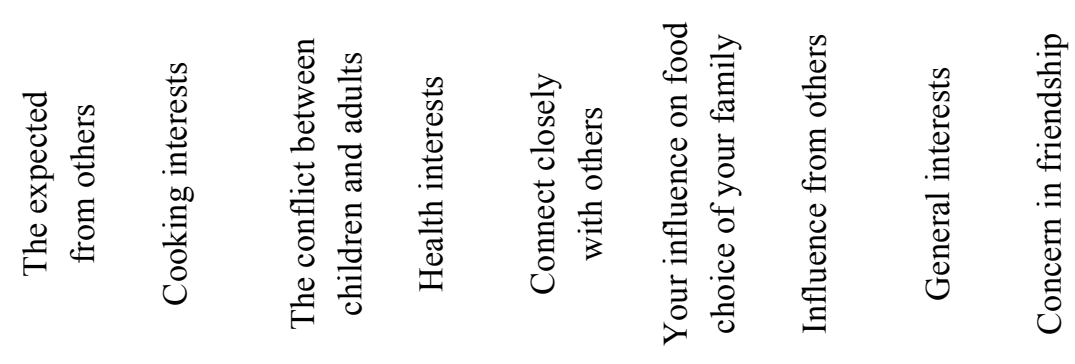

You consider yourself .647

a thin person

skip dinner

You have tried dieting

You don't trust food

You feel strongly tied

to your teachers

You feel very close to

your parents

You spend a lot of time

on your homework

You try to give your

.692

parents tips

Children should be al-

lowed

Adults like food that is

different

Your friends and you

have the same opinion

You have great influ-

ence

Your friends like fish 


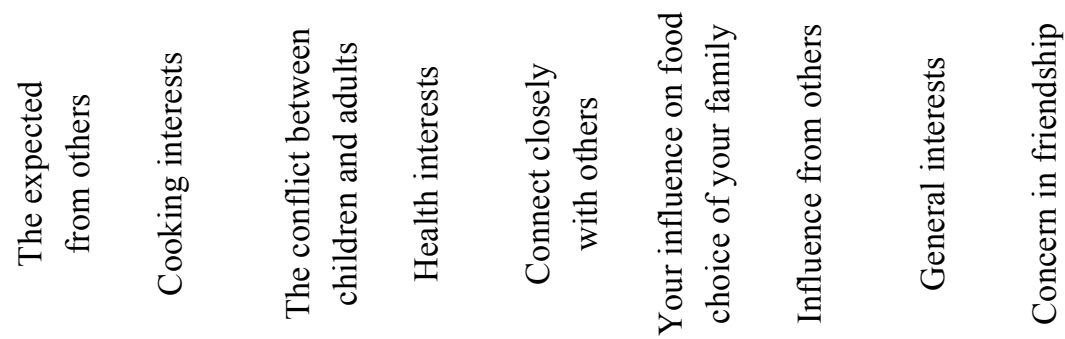

You are very interested

in sports

You are interested in

reading

You are very interested

in environmental issues

You spend a lot of time

with your friends

You feel strongly tied

to your friends

Extraction method: principal component analysis

Rotation method: Varimax with Kaiser normalization

${ }^{\text {a }}$ Rotation converged in 7 iterations

The results in Table 1 shows that item factor loadings are all greater than 0.5. Cronbach's alpha coefficients are all greater than 0.6 regarding several variables The expected from others, The conflict between children and adults, Influence from others, Your influence on food choice of your family, Cooking interests, Health interests, General interests and Concern in friendship. The indices of reliability are greater than the recommended level of 0.6 , but not exceeding 0.8 . The nine factors below explain $57.578 \%$ of variance in the data.

We adopt the traditional two-step approach (Punj \& Stewart, 1983) to identify segments of consumers based on dish preference. Originally, there are 36 dish items in the questionnaire. Items with many "never tasted" scores (more than $13 \%$ ) and multiple factor loadings in the exploratory factor analysis are eliminated 
(26 dish items). Seven factors are extracted (see Table 2), and summated scales are used in subsequent analyses.

Table 2 presents Vietnamese teenagers' preferences for the dishes studied. The first factor is labeled Pork dishes (alpha $=$ 0.80 ), the second factor, Vegetables dishes
$($ alpha $=0.75)$, the third factor, Shellfish dishes (alpha $=0.79$ ), the fourth factor, Eggs dishes (alpha $=0.76)$, the fifth factor, Poultry dishes (alpha $=0.75)$, the sixth factor, Fish dishes (alpha $=0.70$ ), and the last factor, Beef dishes (alpha = 0.71). Summated scales derived from the factors are used in subsequent analyses.

\section{Table 2}

Results of exploratory factor analysis of dishes preference: Rotated factor patterns (Varimax)

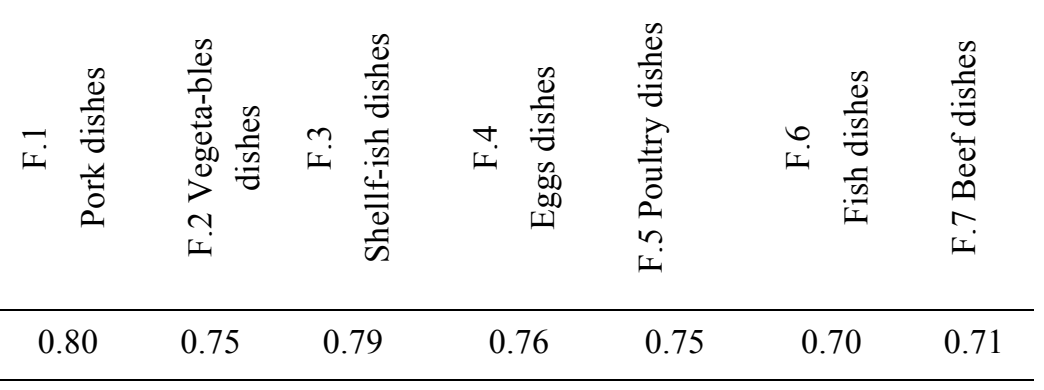

\begin{tabular}{|c|c|c|c|c|c|c|c|}
\hline Cronbach's alpha & 0.80 & 0.75 & 0.79 & 0.76 & 0.75 & 0.70 & 0.71 \\
\hline Stew pork & .770 & & & & & & \\
\hline Pork cook with brine & .732 & & & & & & \\
\hline Steamed pork & .722 & & & & & & \\
\hline Pork soup & .721 & & & & & & \\
\hline Boiled pork & .636 & & & & & & \\
\hline Boiled vegetables & & .836 & & & & & \\
\hline Soup vegetables & & .774 & & & & & \\
\hline Fried vegetables & & .737 & & & & & \\
\hline Raw vegetables & & .606 & & & & & \\
\hline Grill shellfish & & & .814 & & & & \\
\hline Steamed shellfish & & & .802 & & & & \\
\hline Fried shellfish & & & .795 & & & & \\
\hline
\end{tabular}




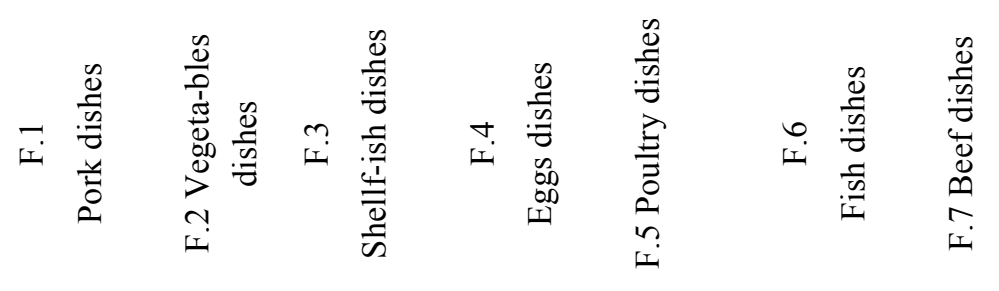

Fried eggs

Omelet eggs

Egg cook with brine

Boiled eggs

Roast poultry

Fried poultry

Grilled poultry

Fish dipped

Fish cooked with

brine

Fried fish

Grill fish

Fried beef/veal

Grilled beef/veal

Beef/veal dish make

of raw beef/veal and vegetables

\section{.808}

.760

.659

.647

.818

.811

.702

.783

.698

.664

.530

.761

.755

.616
A final cluster solution reveals four segments (see Table 3). "Food likers" (29\%) is the largest, representing teenagers who like or are indifferent to all dishes. Specifically, pork dishes and vegetable dishes are the most preferred, followed by seafood dishes. "Poultry dislikers" (27\%) have below average preference scores for most dishes, especially poultry dishes (-1.06). "Seafood dislikers" (19\%) have negative scores on shellfish (-0.84), beef $(-0.56)$, and fish dishes (-0.54). "Pork dislikers" $(25 \%)$ have the lowest scores on pork dishes (-0.91) and vegetable dishes (-0.43). 


\section{Table 3}

Cluster descriptors of dish preferences

\begin{tabular}{|c|c|c|c|c|c|}
\hline Dish preferences: & $\begin{array}{l}\text { Food } \\
\text { likers } \\
(29 \%)\end{array}$ & $\begin{array}{c}\text { Poultry } \\
\text { dislikers } \\
(27 \%)\end{array}$ & $\begin{array}{c}\text { Seafood } \\
\text { dislikers } \\
(19 \%)\end{array}$ & $\begin{array}{c}\text { Pork } \\
\text { dislikers } \\
(25 \%)\end{array}$ & $F(p):$ \\
\hline $\begin{array}{l}\text { Pork dishes } \\
(\alpha=0.80) \text { : }\end{array}$ & 0.50 & -0.15 & 0.62 & -0.91 & $75.82(0.000)$ \\
\hline $\begin{array}{l}\text { Vegetable dishes } \\
(\alpha=0.75):\end{array}$ & 0.50 & -0.25 & 0.14 & -0.43 & $22.45(0.000)$ \\
\hline Shellfish dishes $(\alpha=0.79)$ : & 0.46 & -0.08 & -0.84 & 0.19 & $35.75(0.000)$ \\
\hline $\begin{array}{l}\text { Egg dishes } \\
(\alpha=0.76)\end{array}$ & 0.21 & -0.65 & 0.34 & 0.19 & $25.34(0.000)$ \\
\hline Poultry dishes $(\alpha=0.75)$ : & 0.03 & -1.06 & 0.46 & 0.77 & $\begin{array}{l}130.66 \\
(0.000)\end{array}$ \\
\hline $\begin{array}{l}\text { Fish dishes } \\
(\alpha=0.70) \text { : }\end{array}$ & 0.47 & -0.12 & -0.54 & -0.02 & $19.21(0.000)$ \\
\hline $\begin{array}{l}\text { Beef dishes } \\
(\alpha=0.71) \text { : }\end{array}$ & 0.22 & 0.01 & -0.56 & 0.15 & $11.86(0.000)$ \\
\hline
\end{tabular}

Notes: The cluster descriptors are based on factor scores, which have a mean of 0 and standard deviation of 1 .

ANOVA with Tukey's post-hoc multiple-comparison test is used.

After the segmentation of the teenagers, profiling of the segments is carried out. Only significant differences are discussed due to space limitations. Food likers and dislikers of poultry have higher consumption of fish dishes (about 3-4 times per week), compared with the other segments. Rice dishes are consumed most frequently among seafood dislikers. Seafood dislikers have been most influenced by others compared with the other segments. The teenagers' influence on food choice is, on the other hand, significantly higher among dislikers of pork dishes. The teenagers also have differences in interest and lifestyle. Dislikers of seafood dishes are more interested in cooking and health than those in the other segments. 


\section{Table 4}

Profiling characteristics of the segments

\begin{tabular}{|c|c|c|c|c|c|c|c|c|}
\hline & $\begin{array}{l}\text { Food } \\
\text { likers }\end{array}$ & $\begin{array}{l}\text { Poultry } \\
\text { dislikers }\end{array}$ & $\begin{array}{l}\text { Seafood } \\
\text { dislikers }\end{array}$ & $\begin{array}{c}\text { Pork } \\
\text { dislikers }\end{array}$ & $\begin{array}{l}\text { To- } \\
\text { tal }\end{array}$ & $\mathrm{F} / \chi^{2}:$ & Sig. & Difference \\
\hline \multicolumn{9}{|c|}{ Consumption frequency: } \\
\hline Fish dishes & 2.7 & 2.6 & 2.4 & 2.4 & 2.5 & 2.723 & .044 & $1,2>4,3$ \\
\hline Rice dishes & 5.0 & 4.4 & 5.4 & 5.1 & 5.0 & 2.977 & .031 & $3>4,1,2$ \\
\hline \multicolumn{9}{|c|}{ Social \& family attitudes: } \\
\hline $\begin{array}{l}\text { Influence by } \\
\text { others }\end{array}$ & 4.35 & 4.22 & 4.53 & 4.01 & 4.27 & 3.122 & .026 & $3>1,2,4$ \\
\hline $\begin{array}{l}\text { Your influence } \\
\text { on food choice } \\
\text { of your family }\end{array}$ & 5.26 & 5.12 & 5.45 & 5.61 & 5.34 & 3.058 & .028 & $4>3,1,2$ \\
\hline \multicolumn{9}{|c|}{ Interests \& lifestyle: } \\
\hline $\begin{array}{l}\text { Cooking inter- } \\
\text { ests }\end{array}$ & 5.17 & 4.83 & 5.33 & 4.82 & 5.02 & 3.568 & .014 & $3>1,2,4$ \\
\hline Health interests & 3.43 & 3.28 & 3.74 & 3.27 & 3.41 & 2.819 & .039 & $3>1,2,4$ \\
\hline City: & & & & & & 42.184 & .000 & \\
\hline Ha Noi & 11.6 & 31.5 & 34.2 & 16.7 & 22.5 & & & \\
\hline Da Nang & 33.1 & 20.7 & 13.9 & 26.5 & 24.5 & & & \\
\hline Nha Trang & 32.2 & 31.5 & 22.8 & 17.6 & 26.6 & & & \\
\hline $\mathrm{Ca} \mathrm{Mau}$ & 23.1 & 16.2 & 29.1 & 39.2 & 26.4 & & & \\
\hline Area: & & & & & & 10.694 & .014 & \\
\hline City & 67.8 & 51.4 & 50.6 & 65.7 & 59.6 & & & \\
\hline \multirow[t]{2}{*}{ Rural } & 32.2 & 48.6 & 49.4 & 34.3 & 40.4 & & & \\
\hline & & & & & & 18.834 & .000 & \\
\hline Near to the sea & 59.5 & 45.0 & 32.9 & 35.3 & 44.6 & & & \\
\hline Far from the sea & 40.5 & 55.0 & 67.1 & 64.7 & 55.4 & & & \\
\hline Age group: & & & & & & 17.405 & .043 & \\
\hline $12-13$ & 24.8 & 33.3 & 39.2 & 25.5 & 30.0 & & & \\
\hline $14-15$ & 22.3 & 34.2 & 25.3 & 36.3 & 29.5 & & & \\
\hline $16-17$ & 36.4 & 19.8 & 21.5 & 24.5 & 26.2 & & & \\
\hline
\end{tabular}




\begin{tabular}{|c|c|c|c|c|c|c|c|c|}
\hline & $\begin{array}{l}\text { Food } \\
\text { likers }\end{array}$ & $\begin{array}{l}\text { Poultry } \\
\text { dislikers }\end{array}$ & $\begin{array}{l}\text { Seafood } \\
\text { dislikers }\end{array}$ & $\begin{array}{c}\text { Pork } \\
\text { dislikers }\end{array}$ & $\begin{array}{l}\text { To- } \\
\text { tal }\end{array}$ & $\mathrm{F} / \chi^{2}:$ & Sig. & Difference \\
\hline $18-20$ & 16.5 & 12.6 & 13.9 & 13.7 & 14.3 & & & \\
\hline Religion: & & & & & & 25.814 & .000 & \\
\hline Buddhism & 49.6 & 33.4 & 27.8 & 37.3 & 38.0 & & & \\
\hline No religion & 36.4 & 42.3 & 60.8 & 54.9 & 47.2 & & & \\
\hline Others & 14.0 & 24.3 & 11.4 & 7.8 & 14.8 & & & \\
\hline
\end{tabular}

There are significant differences between the segments with respect to the cities they live in. Food likers living in central Vietnam (i.e. Da Nang and Nha Trang) account for the largest proportions. Seafood dislikers are clearly dominated by $\mathrm{Ha}$ Noi teenagers, and the proportion is also relatively high among adolescents in $\mathrm{Ca}$ Mau. In contrast, the proportion of seafood dislikers is the smallest in Da Nang. Poultry dish dislikers are dominated by teenagers from Ha Noi and Nha Trang. Most of the pork dish dislikers reside in Ca Mau.

Food likers aged between 16 and 17 make up the highest proportion, while poultry dislikers have the lowest share. Seafood dislikers have the highest share among the youngest teenagers (aged from 12 to 15$)$. The majority of pork dislikers are between 14 and 15 years old. There are also significant differences between the segments as to whether they live in rural areas or in the cities. General food likers and dislikers of pork dishes are likely to live in cities. In contrast, dislikers of seafood and poultry are likely to reside in rural areas. Food likers live near the sea, while seafood dislikers and pork dislikers are likely to inhabit somewhere far from the sea. Religion seems to be a differential factor. General food liker segment is dominated by Buddhist teenagers. All the other segments feature the largest shares of non-religious teenagers. There are no significant differences with respect to gender, family size, and the number of children in the household.

\subsection{Discussion}

Evaluating the usefulness of preference-based segmentation in understanding food-related behavior is of major importance to marketers, from both academic and practical perspectives. However, no study is conducted in the context of emerging markets like Vietnam. This study shows that dish preferences are an appropriate basis for segmenting the food and dish market among Vietnamese teenagers. Four teenager segments have been identified. Differences between the segments 
have also been profiled using a diverse set of variables. The differences found across the segments for the differentiating variables can provide the basis for developing marketing strategies of targeting and positioning within different segments.

This research is built on extant studies on food consumption behavior among adolescents (Birch, 1999; Drewnowski \& Hann, 1999; Halford et al., 2008; Hoelscher et al., 2002; Honkanen et al., 2004; Skinner et al., 2002; Story et al., 2002; Olsen et al., 2009; Arechavala et al., 2016), and is adapted for specific Vietnamese conditions. Dishes commonly served as main meals in Vietnamese households are identified. The findings confirm that preferences are important in food studies given their significant relationship with consumption behaviors. Also, there are marked differences in preferences among Vietnamese teenagers. The results are in accordance with several earlier studies (Berg et al., 2000; Honkanen et al., 2004), indicating that teenagers are less concerned with healthy dishes and that many of them dislike seafood. The results also support the fact that social factors are crucial in explaining and categorizing different preference segments. Often used variables such as gender, family size, and the number of children in the household are not significant factors in explaining preference-based segments. An important result suggests that differences in food preferences of adolescents depend on the region in which they reside.

\section{Conclusion and policy implications}

The adolescent period is such that individuals become more independent consumers and exert increased independence and a subsequent freedom of preference (Brown et al., 2000). Preferences can be an appropriate basis for segmentation, providing insights into the depth of teenagers' dish market. This suggests implications for marketers, retailers, and school canteens as well as for public policy makers in terms of effectively targeting different market segments of teenagers.

Retailers, restaurants, and school canteens are operating commercially in Vietnam and must provide different kinds of food that adolescents want and desire. To cater for specific segments, these businesses need to be informed of children's dish preferences. Retailers, restaurants, school canteens, and institutions may find preference-based segmentation beneficial for their businesses. Meal suppliers can use this knowledge to identify the segments most likely to be attracted to their product offerings. These inputs can also be fed into strategic activities to enhance their 
image, including decisions about assortment and service to suit various target segments. In order to meet teenagers' selection criteria, meal providers must be able to supply novel dishes preferred by teenagers themselves.

For example, if a seafood dish supplier intends to target the dislikers of seafood, it should improve the marketing mix strategies. Suppliers should focus on improving the sensory aspects of their offerings. This is to enhance teenagers' positive attitudes toward consumption of seafood dishes. Most young consumers in this segment live far from the sea, which means that seafood may not be available in these areas, suggesting implications for the distribution channels' effectiveness. As for promotion, teenagers in this segment are highly engaged in home cooking and have general interest in environmental issues, sports, and reading. Retailers, restaurants, school canteens, and institutions, therefore, should utilize such characteristic in their promotion activities.

Additionally, this study has practical implications for policy makers. Three clusters are characterized by dislikes of specific dishes. In order to promote a balanced and healthy diet among those adolescents, policy makers can adopt the preference-based segments to target adolescents with specific information and attitude-change campaigns. The segment profiles give access to their attitudes, lifestyle, interests, and demographics, providing a steppingstone to develop relevant information and campaigns in order to change their attitudes toward food and health.

Most of the constructs used in this study are developed and validated in a Western setting. Future research should validate these constructs in an Asian or Vietnamese setting in order to secure reliable and valid scales across cultures. This study has limitations that should be taken into consideration. While the convenient sampling is utilized, the sample size is smaller than desired, which eliminates the use of process evaluation and the use of statistics to analyze the quantitative findings. A larger sample, hence, would have allowed for more statistical analysis. Furthermore, due to the nature of this study, the results may not be representative to all adolescents in Vietnam, which is to be improved in further research.

\section{References}

Ajzen, I. (2002). Constructing a TPB questionnaire: Conceptual and methodological considerations. Retrieved May 18, $2010 \quad$ from http://www.people.umass.edu/aizen/pdf/ tpb.measurement.pdf 
Arechavala, T., Continente, X., Pérez-Giménez, A., Bartoll, X., Sànchez-Martínez, F., \& López, M. J. (2016). Food consumption frequency and excess body weight in adolescents in the context of financial crisis in Barcelona (Spain). Gaceta Sanitaria, 30(6), 457-463.

Ares, G., \& Gambaro, A. (2007). Influence of gender, age and motives underlying food choice on perceived healthiness and willingness to try functional foods. Appetite, 49(1), 148-158.

Beane, T. P., \& Ennis, D. M. (1987). Market segmentation: A review. European Journal of Marketing, 21(5), 20-42.

Berg, C., Jonsson, I., \& Conner, M. (2000). Understanding choice of milk and bread for breakfast among Swedish children aged 11-15 years: An application of the theory of planned behavior. Appetite, 34(1), 5-19.

Bernues, A., Olaizola, A., \& Corcoran, K. (2003). Extrinsic attributes of red meat as indicator of quality in Europe: An application for market segmentation. Food Quality and Preference, 14(4), 265-276.

Birch, L. (1999). Development of food preferences. Annual Review of Nutrition, 19(1), 41-62.

Brown, K., McIlveen, H., \& Strugnell, C. (2000). Young consumers' food preferences within selected sectors of the hospitality spectrum. Journal of Consumer Studies \& Home Economics, 24(2), 104112.

Byrd-Bredbenner, C., \& Grasso, D. (2000). What is television trying to make children swallow? A content analysis of nutrition information embedded in prime-time advertisements. Journal of $\mathrm{Nu}$ trition Education, 32(4), 187-195.

Chisnall, P. M. (1985). Marketing: A behavioral analysis (2nd Ed.). McGraw-Hill Book Company (UK) Ltd., Maidenhead.

Cong, L. C., Olsen, S. O., \& Tuu, H. H. (2012). The roles of ambivalence, preference conflict, and family identity: A study of food choice among Vietnamese consumers. Food Quality and Preference, 28(1), 92-100.

Delarue, J., \& Loescher, E. (2004). Dynamics of food preferences: A case study with chewing gum. Food Quality and Preference, 15(7-8), 771-779.

Drewnowski, A. (1997). Taste preferences and food intake. Annual Reviews Nutrition, 17(1), 237253.

Drewnowski, A., \& Hann, C. (1999). Food preferences and reported frequency of consumption as predictors of current diet in young women. American Journal of Clinical Nutrition, 70(1), 28-36.

Eagly, A. H., \& Chaiken, S. (1993). The psychology of attitudes. Harcourt Brace Jovanovich College Publishers, Fort Worth, TX.

Engel, J. F., Blackwell, R. D., \& Miniard, P. W. (1996). Consumer behavior (7th Ed.). The Dryden Press, Hinsdale, IL.

Fishbein, M., \& Ajzen, I. (1975). Belief, attitude, intention and behavior: An introduction to theory 
and research. Addison-Wesley Publishing Company, Inc.

Frank, R., Massy, W. F., \& Wind, Y. (1972). Market segmentation. Prentice-Hall, Englewood Cliffs, NJ.

Furst, T., Connors, M., Bisogni, C. A., Sobal, J., \& Falk, L. W. (1996). Food choice: A conceptual model of the process. Appetite, 26(3), 247-266.

Gummeson, L., Jonsson, I., Conner, M. T., \& Svensson, E. (1996). Assessing factors influencing food choice among 10-16-year-old schoolboys: A pilot study with a stacking box method. Journal of Human Nutrition and Dietetics, 9(3), 219-229.

Haley, R. I. (1968). Benefit segmentation: A decision-oriented research tool. Journal of Marketing, 32(3), 30-35.

Halford, J. C. G., Boyland, E. J., Cooper, G. D., Dovey, T. M., Smith, C. J., Williams, N., \& Blundell, J. E. (2008). Children's food preferences: Effects of weight status, food type, branding and television food advertisements (commercials). International Journal of Pediatric Obesity. Retrieved from http://www.informaworld.com/smpp/title $\sim \mathrm{db}=$ all $\sim$ content $=\mathrm{t} 725414071 \sim \mathrm{tab}=\mathrm{is}-$ sueslist $\sim$ branches $=3-\mathrm{v} 33(1), 31-38$.

Hoelscher, D. M., Evans, A., Parcel, G. S., \& Kelder, S. H. (2002). Designing effective nutrition interventions for adolescents. Journal of the American Dietetic Association, 102(3), 52-63.

Honkanen, P. (2010). Food preference based segments in Russia. Food Quality and Preference, 21(1), 65-74.

Honkanen, P., \& Frewer, L (2009). Russian consumers' motives for food choice. Appetite, 52(2), 363-371.

Honkanen, P., Olsen, S. O., \& Myrland, O. (2004). Preference-based segmentation: A study of meal preferences among Norwegian teenagers. Journal of Consumer Behavior, 3(3), 235-250.

Horwath, C. C. (1990). Food frequency questionnaires: A review. Australian Journal of Nutrition and Dietetics, 47(3), 46-71.

Kardes, F. R. (1999). Consumer behavior: Managerial decision making. Addison Wesley Longman, NY.

Kucukemiroglu, O. (1999). Market segmentation by using consumer lifestyle dimensions and ethnocentrism: An empirical study. European Journal of Marketing, 33(5-6), 470-487.

Logue, A. W., \& Smith, M. E. (1986). Predictors of food preferences in adult humans. Appetite, 7(2), $109-125$.

Louw, D. A. (2002). Human development. Kagiso, Johannesburg, South Africa.

McCarthy, M., \& Henson, S. (2005). Perceived risk and risk reducing strategies in the choice of beef by Irish consumers. Food Quality and Preference, 16(5), 435-445.

Ngapo, T. M., Martin, J. F., \& Dransfield, E. (2007). International preferences for pork appearance: Consumer choices. Food Quality and Preference, 18(1), 26-36. 
Nielsen, N. A., Bech-Larsen, T., \& Grunert, K. G. (1998). Consumer purchase motives and product perceptions: A laddering study on vegetable oil in three countries. Food Quality and Preference, $9(6), 455-466$.

Olsen, S. O. (2001). Consumer involvement in seafood as family meals in Norway: An application of the expectancy-value approach. Appetite, 36(2), 173-186.

Olsen, S. O. (2003). Understanding the relationship between age and seafood consumption: The mediating role of attitude, health involvement and convenience. Food Quality and Preference, 14(3), 199-209.

Olsen, S. O. (2004). Antecedents of seafood consumption behavior: An overview. Journal of Aquatic Food Product Technology, 13(3), 79-91.

Olsen, S. O., Prebensen, N., \& Larsen, T. A. (2009). Including ambivalence as a basis for benefit segmentation: A study of convenience food in Norway. European Journal of Marketing, 43(5-6), $762-783$.

Olsen, S. O., \& Ruiz, S. (2008). Adolescents' influence in family meal decisions. Appetite, 51(3), 646-653.

Punj, G., \& Stewart, D. W. (1983). Cluster analysis in marketing research: Review and suggestions for applications. Journal of Marketing Research, 20(2), 134-148.

Quinn, L., Hines, T., \& Bennison, D. (2007). Making sense of market segmentation: A fashion retailing case. European Journal of Marketing, 41(5-6), 439-465.

Raats, M. M., Shepherd, R., \& Sparks, P. (1995). Including moral dimensions of choice within the structure of the theory of planned behavior. Journal of Applied Social Psychology, 25(6), 484494.

Roininen, K., Lähteenmäki, L., \& Tourila, H. (1999). Quantification of consumer attitudes to health and hedonic characteristics of foods. Appetite, 33(1), 71-88.

Rozin, P. (1996). The socio-cultural context of eating and food choice. In H. L. Meiselman \& H. J. H. MacFie (Eds.), Food choice, acceptance and consumption (pp. 83-104). Blackie Academic, London.

Shepherd, R. (1989). Factors influencing food preferences and choice. In R. Shepherd (Ed.), Handbook of the psychophysiology of human eating (pp. 3-24). John Wiley, NY.

Shepherd, R., \& Raats, M. M. (1996). Attitudes and beliefs in food habits. In H. L. Meiselman \& H. J. H. MacFie (Eds.), Food choice acceptance and consumption (pp. 346-364). Blackie Academic and Professional, London.

Skinner, J. D., Carruth, B. R., Bounds, W., \& Ziegler, P. J. (2002). Children's food preferences: A longitudinal analysis. Journal of the American Dietetic Association, 102(11), 1638-1647.

Steptoe, A., Pollard, T., \& Wardle, J. (1995). Development of a measure of the motives underlying the selection of food: The food choice questionnaire. Appetite, 25(3), 267-284. 
Story, M., Neumark-Sztainer, D., \& French, S. (2002). Individual and environmental influences on adolescent eating behaviors. Journal of the American Dietetic Association, 102(3), 40-51.

Sukalakamala, S., \& Brittin, H. C. (2008). Food practices and preferences of Thais in the United States. Journal of the American Dietetic Association, 106(1), 103-108.

Ton Nu, C., MacLeod, P., \& Barthelemy, J. (1996). Effects of age and gender on adolescents' food habits and preferences. Food Quality and Preference, 7(3-4), 251-262.

Tuu, H. H., Olsen, S. O., Thao. D. T., \& Kim Anh, N. T. (2008). The role of norms in explaining attitudes, intention and consumption of a common food (fish) in Vietnam. Appetite, 51(3), 546551.

Tynan, A. C., \& Drayton, J. (1987). Market segmentation. Journal of Marketing Management, 2(3), 301-335.

Verbeke, W., \& Lopez, G. (2005). Ethnic food attitudes and behavior among Belgians and Hispanics living in Belgium. British Food Journal, 107(10-11), 822-840.

Verbeke, W., \& Vackier, I. (2005). Individual determinants of fish consumption: Application of the theory of planned behavior. Appetite, 44(1), 67-82.

Verbeke, W., Vermeir, I., \& Brunsø, K. (2007). Consumer evaluation of fish quality as basis for fish market segmentation. Food Quality and Preference Food, 18(4), 651-661.

Wedel, M., \& Desarbo, W. S. (2002). Market segment derivation and profiling via a finite mixture model framework. Marketing Letters, 13(1), 17-25.

Wedel, M., \& Kamakura, W. A. (1998). Market segmentation: Conceptual and methodological foundations. Kluwer Academic Publishers, London, UK.

Wells, W., \& Tigert, D. (1977). Activities, interests, and opinions. Journal of Advertising Research, 11(4), 27-35.

Williams, P. R. D., \& Hammit, J. K. (2001). Perceived risks of conventional and organic produce: Pesticides, pathogens, and natural toxins. Risk Analysis, 21(2), 319-330.

Wind, Y. (1978). Issues and advances in segmentation research. Journal of Marketing Research, 15(3), 317-338. 